\title{
Formability of Cryorolled Aluminum Alloy Sheets in Warm Forming
}

\author{
D. Raja Satish, Fitsum T. Feyissa, and D. Ravi Kumar
}

\begin{abstract}
Aluminium alloys are widely used in automobile industry due to their high strength to weight ratio, excellent corrosion resistance and easy machinability making them an alternative material to low carbon steel. But, one of the limitations of aluminum alloy sheets is their inferior strength and formability at room temperature when compared to low carbon deep drawing grade steels. Cryorolling is a severe plastic deformation process used to obtain ultra-fine grain structure in aluminium alloys along with high strength. However, it results in poor ductility and formability. Formability can be enhanced by warm forming, in which sheets metals are formed into desired shape at elevated temperatures but below the recrystallization temperature combining the advantages of both cold working and hot working. In this work, a hybrid processing route has been developed to enhance strength as well as formability of AA5083 alloy by cryorolling followed by warm forming. AA5083 aluminium alloy sheets of $5 \mathrm{~mm}$ thickness were solutionized at $530{ }^{\circ} \mathrm{C}$ followed by water quenching. These sheets were cryorolled to $1 \mathrm{~mm}$ thickness with $80 \%$ thickness reduction. Formability in biaxial stretch forming (in terms of limiting dome height) of these sheets was characterized at room temperature and elevated temperatures $\left(200^{\circ} \mathrm{C}, 250^{\circ} \mathrm{C}\right.$ and $\left.300^{\circ} \mathrm{C}\right)$. Formability of the cryorolled sheets has been enhanced by forming in the warm working temperature range. The limit strains and limiting dome height have been found to be higher than in the case of conventional processing route (cold rolled, annealed and formed at room temperature) making this process capable of producing sheet metal parts of aluminium alloys with high strength and better formability.
\end{abstract}

Index Terms-Aluminium alloy, Cryorolling, Formability, Warm forming

\section{INTRODUCTION}

Due to high emissions, recyclability and increased fuel prices problems, automobile industries are trying to produce light weight vehicles. In this scenario, use of aluminium alloys become alternative to steels in automobile industries because of its low strength to weigh ratio, $99 \%$ recyclability, higher fuel efficiency and environmental advantages [1] . Adopting aluminium alloys in automobile is still questionable due to relatively higher cost, poor formability, poor final strength, stiffens and dent resistance. Therefore, aluminium alloys with combination of very high strength and satisfactory ductility, leading to a high potential for light-weight automobiles. The introduction of severe plastic deformation to aluminium sheet significantly changes the microstructure with leads to high strength but poor formability[2]. To achieve ultrafine grains (UFG) structured materials, severe plastic deformation (SPD)

Manuscript received November 20, 2016; revised April 5, 2017.

The authors are with the Indian Institute of Technology Delhi, New Delhi, India 110016 (e-mail: srdommeti@gmail.com, fitsum.tf@gmail.com, draviiitd@gmail.com). processes like equal channel angular pressing [3], repetitive corrugation and straightening [4], accumulative roll bonding [5] and high-pressure torsion [6] were used and requires, large plastic deformations, special tooling and adopting these processes in industries is difficult. An alternative method for producing UFG structure in the material is rolling at cryogenic temperatures which is generally referred as cryorolling [7]. Unlike other SPD processes, cryorolling does not require specialized forming equipment and it is much easier to adopt in industries. Suppression of dynamic recovery and dislocation density leads to finer grains and gives high strength to the material [8]. Microstructural studies of cryorolled sheets has been studied by many researchers [9]-[11] and found ultrafine grain structure. It is well known that the fine grain structure leads to higher yield strength and strain rate sensitivity but leads to poor tensile elongation. Several studies [10], [12]-[14] show that, improvement in ductility of $\mathrm{Al}$ alloys has been observed by low temperature annealing. Till now only few studies have been focused on the formability of $\mathrm{Al}$ alloys sheets produced by cryorolling. Some studies show that even though the tensile elongation of cryorolled sheets is poor their stretchability and drawability is considerably high. To improve the formability of sheets metals, unconventional processes like hydroforming, superplastic forming and warm forming can be used. Forming of $\mathrm{Al}$ alloys improved the formability of the materials of coarse grained sheets in the warm working temperature range $(0.3 \mathrm{Tm}-0.5 \mathrm{Tm})$ where $\mathrm{T}_{\mathrm{m}}$ is melting point temperature of the material [15], [16]. In this work formability of cryorolled sheets in the warm working temperature range is studied. Limiting dome height, major and minor strain distributions were measured and reported. For comparison, cold rolled and annealed sheets (conventional sheets) formed at room temperature were taken.

\section{Methodology}

\section{A. Material Selection, Chemical Composition and Microstructure}

$\mathrm{Al}-\mathrm{Mg}$ alloys are widely used in automotive and aircraft industries. In this study, AA5083 alloy sheets of $5 \mathrm{~mm}$ thickness were selected. The chemical composition of this alloys analyzed using spectroscopy and were given in Table I

TABLE I: CHEMICAL COMPOSITION OF AA5083 ALLOY

\begin{tabular}{llllllll}
\hline \hline $\mathbf{M g}$ & $\mathbf{M n}$ & $\mathbf{F e}$ & $\mathbf{S i}$ & $\mathbf{C u}$ & $\mathbf{C r}$ & $\mathbf{Z n}$ & Al \\
\hline 4.256 & 0.542 & 0.221 & 0.258 & 0.047 & 0.086 & 0.030 & Balance \\
\hline \hline
\end{tabular}

Microstructural studies are conducted using Keller's 
reagent by optical microscope. Fig. 1 (a) \& (b) shows microstructure of cryorolled sheets with $70 \%$ thickness reduction and cold rolled annealed sheets respectively. The microstructure revealed for cryorolled sheets shows fragmentation of grains and ill-defined grain boundaries. Whereas the optical micrograph of sheets produced by cold rolling at annealed condition revealed coarse grains.

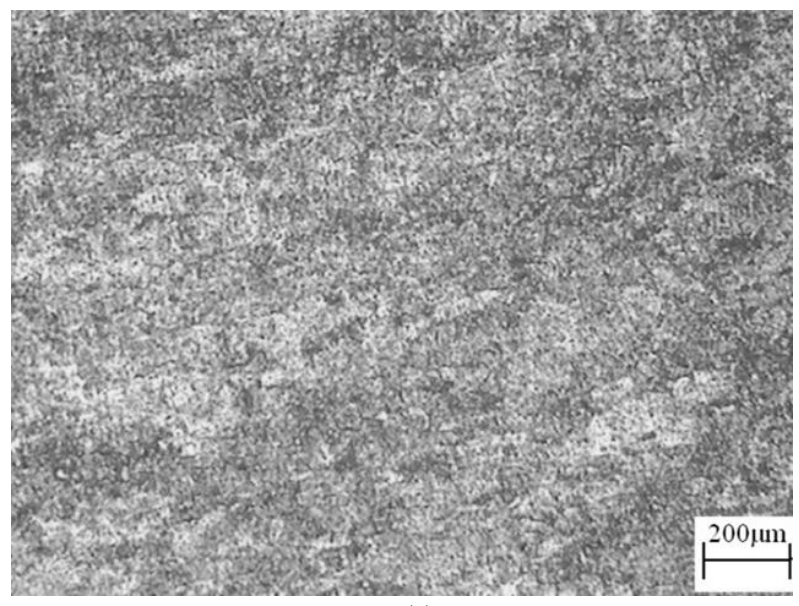

(a)

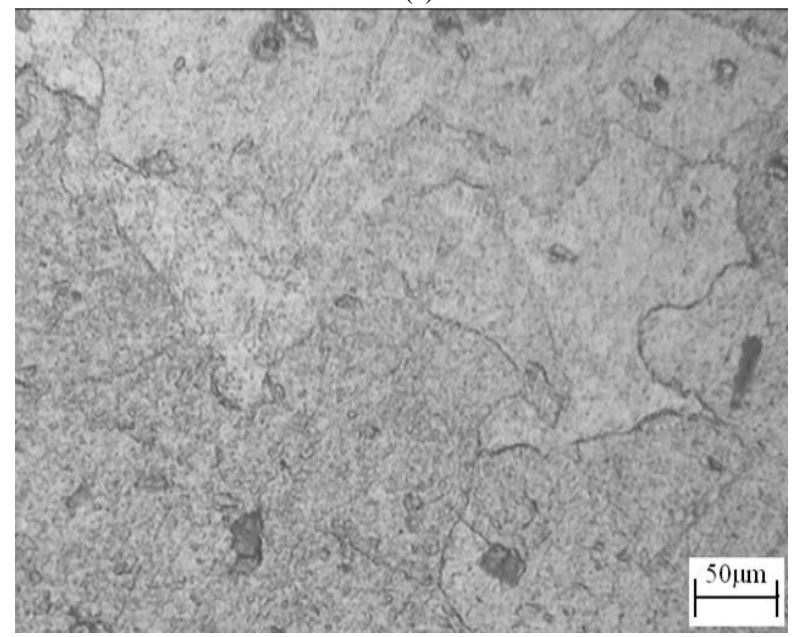

(b)

Fig. 1. Microstructure of AA5083 alloy (a) As cryorolled sheet with 70\% thickness reduction (b) coldrolled and annealed sheet with $80 \%$ thickness reduction.

\section{B. Material Processing and Sample Preparation}

The sheets of $5 \mathrm{~mm}$ thickness were solutionized at $530^{\circ} \mathrm{C}$ for $2 \mathrm{~h}$ and water quenched to achieve homogenous solid solution in the material [17]. Cryorolling is performed on 4 high rolling mill machine using liquid nitrogen as shown in Fig 1. Initially the sheets were dipped in liquid nitrogen bath $\left(-196^{\circ} \mathrm{C}\right)$ for $30 \mathrm{~min}$ and in between each pass, sheets were dipped in liquid nitrogen for $10-15 \mathrm{~min}$. During each pass $4 \%$ reduction is given by adjusting the roll gap. Cryorolled sheets of $1 \mathrm{~mm}$ thickness were produced after thickness reduction of $80 \%$. Conventional sheets of $1 \mathrm{~mm}$ thickness are also produced by rolling at room temperature followed by annealing at $300^{\circ} \mathrm{C}$ then water quenched.

\section{Determination of Mechanical Properties}

Cryorolled and conventional sheets were prepared as per ASTM-E8 standard for conducting tensile tests. Uniaxial tensile tests were carried out on INSTRON 5582 with cross head speed of $2.5 \mathrm{~mm} / \mathrm{min}$. Engineering stress-strain curves were plotted using load-displacement data. Mechanical properties like yield strength (YS), ultimate tensile strength (UTS) and ductility (\%elongation) were measured. Hardness is measured using Vickers hardness tester with test load of $200 \mathrm{gm}$ and $15 \mathrm{sec}$ dwell time.

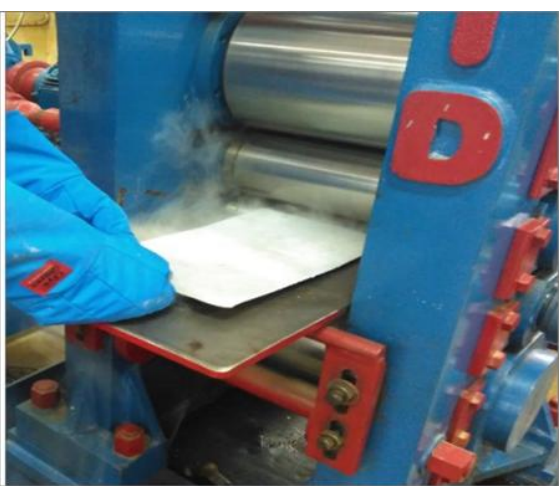

Fig. 2. Experimental setup for cryorolling.

\section{FORMABILITY AT ELEVATED TEMPERATURES}

To characterize formability in biaxial tension mode of deformation, Limiting Dome Height Tests (LDH) were conducted. To study the formability of cryorolled sheets in warm working temperature range $\left(0.3 T_{m}-0.5 T_{m}\right.$, where $\mathrm{Tm}$ is absolute melting temperature) [18], LDH tests were carried out at three different temperature: $200^{\circ} \mathrm{C}, 250^{\circ} \mathrm{C}$ and $300^{\circ} \mathrm{C}$ (below recrystallization temperature of AA5083 alloy) on double action hydraulic press of 80T capacity with the help of heated tooling arrangement as shown in Fig. 3. The hemispherical bottom punch of $50 \mathrm{~mm}$ diameter is heated by high-watt cartridge heater and dies were heated using casing heaters. The temperature in the tools is controlled and regulated using PID controller. Thermocouples were used to measure temperature in the dies during the tests. The temperature variation during the tests was $\pm 10^{\circ} \mathrm{C}$. The blanks were preheated to the test temperature and were transferred to the heated dies. An optimum blank holding force is applied to avoid material flow from the flange region. The punch displacement was stopped at the point of necking/failure observed in the sample.

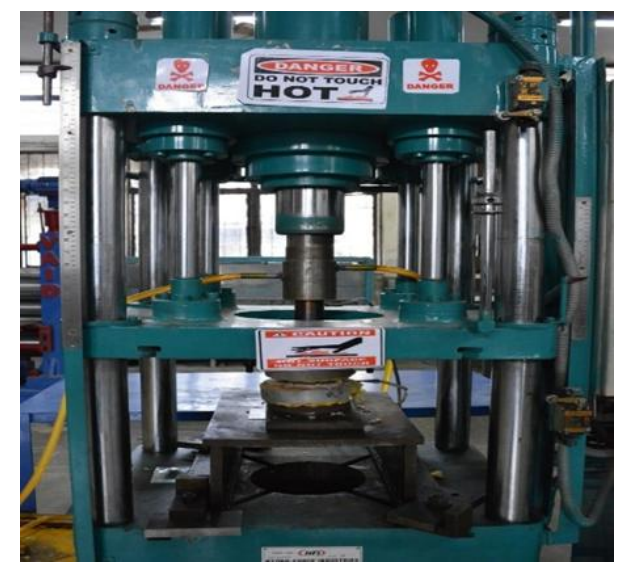

Fig. 3. Experimental set up for warm forming.

Major and minor principal strains were calculated by measuring major and minor diameters of ellipses on the tested samples using a digital microscope. Limiting dome heights of all the specimens at the onset of necking/failure was measured using vernier height gauge. 


\section{EXPERIMENTAL RESULTS}

\section{A. Tensile Properties and Hardness}

Engineering stress-strain curves of AA5083 alloy sheets are shown in Fig. 4. Mechanical properties of AA5083 are given in Table II. Tensile strength and yield strength of cryorolled sheet significantly improved due to suppression of dynamic recovery and accumulation of high dislocation density. The average Vickers micro hardness value of cryorolled is found to be $153 \mathrm{HV}$ which is much higher than hardness of cryorolled sheets. However, ductility of cryorolled sheets in the as-rolled condition is very poor when compared to conventionally rolled (CR) and annealed sheets which makes forming these sheets at RT extremely difficult.

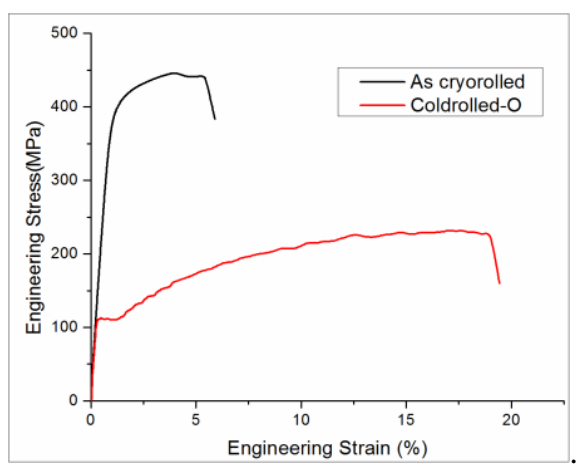

Fig. 4. Engineering stress-strain curve of AA5083 at different conditions.

TABLE II: MECHANICAL PROPERTIES OF AA5083

\begin{tabular}{llllc}
\hline \hline Condition & YS & UTS & Elong. & Hardness \\
\hline Coldrolled+Annealed & $109 \mathrm{MPa}$ & $232 \mathrm{MPa}$ & $19.5 \%$ & $85 \mathrm{HV}$ \\
Cryorolled & $366 \mathrm{Mpa}$ & $448 \mathrm{MPa}$ & $5.5 \%$ & $153 \mathrm{HV}$ \\
\hline \hline
\end{tabular}

\section{B. Formability Tests}

The LDH samples tested at different temperatures are shown in Fig. 5. The LDH values of cryorolled sheets formed at different temperatures and cold rolled and annealed sheet formed at room temperature are given in Fig. 6. It has been observed that LDH of cryorolled sheet at room temperature is very low due to low strain hardening ability which implies cryorolled sheets are very difficult to form at room temperature. Improvement in formability of cryorolled sheets has been observed with increase in forming temperature from $200^{\circ} \mathrm{C}$ to $300^{\circ} \mathrm{C}$. $\mathrm{LDH}$ of cryorolled sheets tested at $250^{\circ} \mathrm{C}$ is higher than that of cold rolled and fully annealed sheet. So, with suitable selection of forming temperature, parts can be produced with better strength and formability.

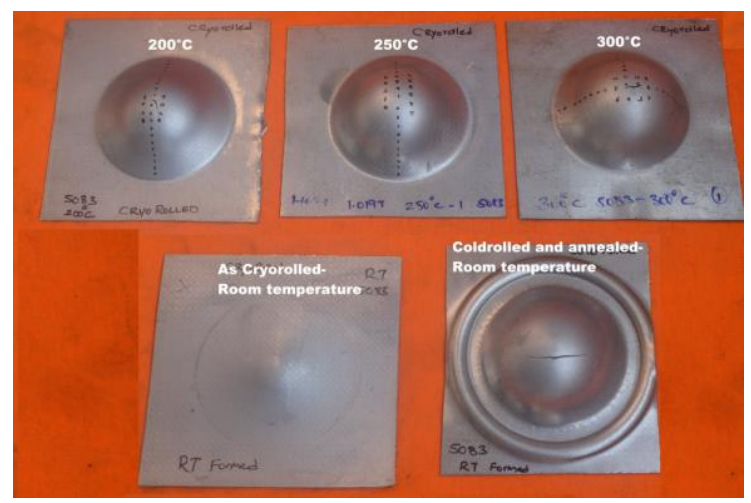

Fig. 5. LDH samples tested at different temperatures.

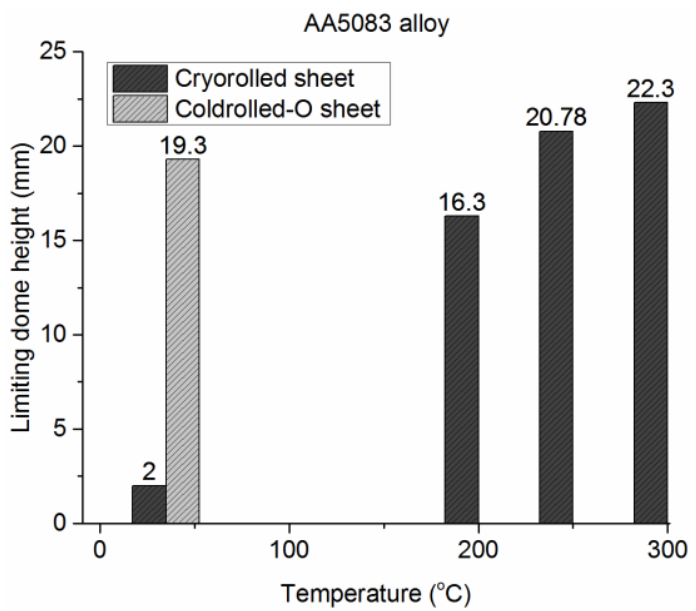

Fig. 6. Limiting dome height of AA5083 tested at different conditions.

Major strain and minor strain values as a function of distance from the pole in the LDH samples, plotted for cryorolled sheets at different temperatures and for conventional sheets tested at room temperature, are shown in Fig. 6 (a) \& (b). From the strain distribution plots, it has been observed that strain peaks for cryorolled sheets tested at all three temperatures occur at the pole region, showing uniform strain distribution in the samples. The peak major and minor strains increased with increase in temperature. Even though the dome height of cold rolled and annealed samples tested at room temperature is higher, the peak major strains are below the cryorolled sheets tested at $200^{\circ} \mathrm{C}$ and this is due to higher strain rate sensitivity at elevated temperatures. The cryorolled sheets exhibit higher peak strains when compared to conventional sheets formed at room temperature.

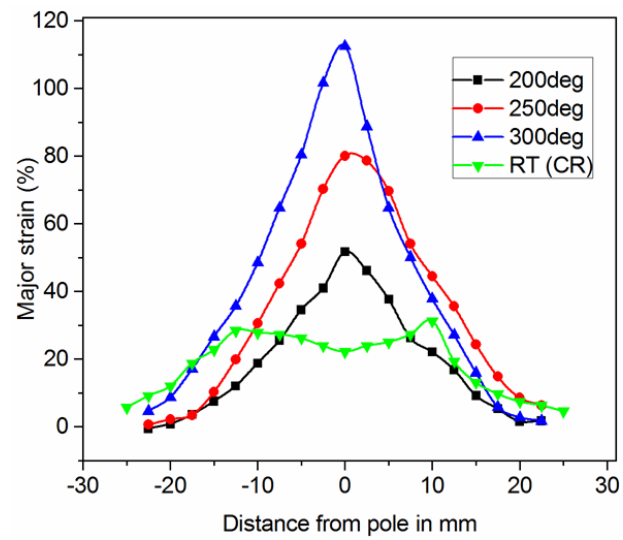

(a)

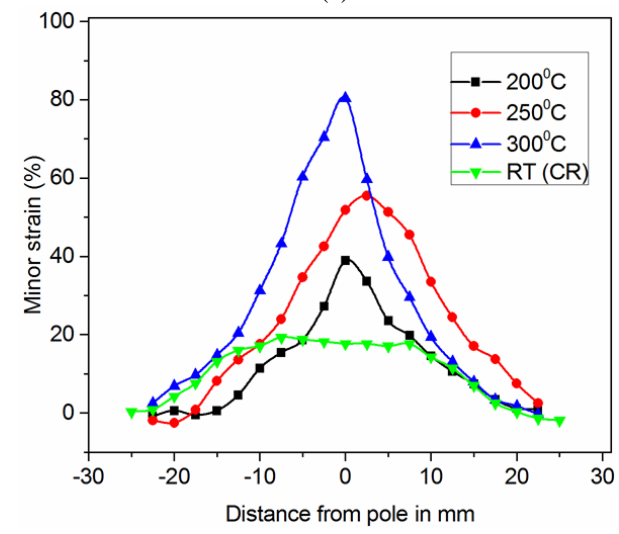

(b)

Fig. 7. Strain distributions (a) Major strains (b) Minor strain of AA5083 tested at different conditions. 


\section{CONCLUSION}

Cryorolled sheets of AA5083 alloy with ultrafine grain structure were produced. Warm forming has been studied to enhance formability of cryorolled sheets.

Formability of cryorolled AA5083 alloy sheets increased significantly in biaxial stretching mode (Limiting Dome Height) at elevated temperatures ranging from $200^{\circ} \mathrm{C}$ to $300^{\circ} \mathrm{C}$ when compared to room temperature. Formability of cryorolled sheets tested at $250^{\circ} \mathrm{C}$ and $300^{\circ} \mathrm{C}$ has been found to be greater than the cold rolled fully annealed samples formed at room temperature. Major and minor strains at necking also increased significantly indicating overall increase in formability. Single peaks in major and minor strain distributions show uniform more strain distribution within the sample. Cryorolling followed by warm forming can be used as a potential method to obtain parts with high strength and enhanced formability.

\section{REFERENCES}

[1] W. S. Miller et al., "Recent development in aluminium alloys for the automotive industry," Materials Science and Engineering: A., vol. 280, no. 1 , pp. 37-49, 2000.

[2] A. Azushima et al., "Severe plastic deformation (SPD) processes for metals," CIRP Annals - Manufacturing Technology, vol. 57, no. 2, pp. 716-735, 2008.

[3] Y. Iwahashi et al., "Principle of equal-channel angular pressing for the processing of ultra-fine grained materials," Scripta Materialia, vol. 35 , no. 2, pp. 143-146, 1996.

[4] R. Z. Valiev, R. K. Islamgaliev, and I. V. Alexandrov, "Bulk nanostructured materials from severe plastic deformation," Prog. Mater. Sci., vol. 45, pp. 103-189, 2000.

[5] Y. Saito et al., "Novel ultra-high straining process for bulk materials-development of the accumulative roll-bonding (ARB) process," Acta Materialia, vol. 47, no. 2, pp. 579-583, 1999.

[6] A. P. Zhilyaev and T. G. Langdon, "Using high-pressure torsion for metal processing: Fundamentals and applications," Progress in Materials Science, vol. 53, no. 6, pp. 893-979, 2008.

[7] T. Shanmugasundaram, B. S. Murty, and V. S. Sarma, "Development of ultrafine grained high strength $\mathrm{Al}-\mathrm{Cu}$ alloy by cryorolling," Scripta Materialia, vol. 54, no. 12, pp. 2013-2017, 2006.

[8] R. Z. Valiev, A. V. Korznikov, and R. R. Mulyukov, "Structure and properties of ultrafine-grained materials produced by severe plastic deformation," Materials Science and Engineering: A, vol. 168, no. 2, pp. 141-148, 1993.

[9] S. K. Panigrahi, R. Jayaganthan, and V. Chawla, "Effect of cryorolling on microstructure of $\mathrm{Al}-\mathrm{Mg}-\mathrm{Si}$ alloy," Materials Letters, vol. 62, pp. 17-18, pp. 2626-2629, 2008.

[10] Y. B. Lee et al., "Effect of annealing temperature on microstructures and mechanical properties of a $5083 \mathrm{Al}$ alloy deformed at cryogenic temperature," Scripta Materialia, vol. 51, no. 4, pp. 355-359, 2004.

[11] N. Rangaraju et al., "Effect of cryo-rolling and annealing on microstructure and properties of commercially pure aluminium," Materials Science and Engineering: A, vol. 398, no. 1-2, pp. 246-251, 2005.

[12] V. S. Sarma et al., "Microstructure and mechanical properties of ultra fine grained $\mathrm{Cu}-\mathrm{Zn}$ and $\mathrm{Cu}-\mathrm{Al}$ alloys produced by cryorolling and annealing," Materials Science and Engineering: A, vol. 489, no. 1, pp. 253-258, 2008.
[13] T. Konkova et al., "Annealing behavior of cryogenically-rolled copper," Materials Science and Engineering: A, vol. 585, pp. 178-189, 2013.

[14] Y. B. Lee, D. H. Shin, and W. J. Nam, "Effect of annealing temperature on tensile behavior of $5052 \mathrm{Al}$ alloy deformed at cryogenic temperature," Journal of Materials Science, vol. 40, no. 5, pp. 1313-1315, 2005.

[15] D. Li and A. K. Ghosh, "Biaxial warm forming behavior of aluminum sheet alloys," Journal of Materials Processing Technology, vol. 145, no. 3, pp. 281-293, 2004.

[16] L.R. Morris and R. A. George, "Warm forming high-strength aluminum automotive parts," SAE Technical Paper, 1977.

[17] Heat Treating, Handbook, 1991.

[18] N. Abedrabbo, F. Pourboghrat, and J. Carsley, "Forming of AA5182-O and AA5754-O at elevated temperatures using coupled thermo-mechanical finite element models," International Journal of Plasticity, vol. 23, no. 5, pp. 841-875, 2007.

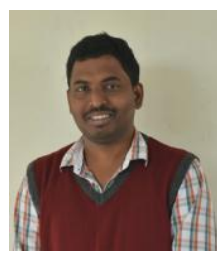

Dommeti Raja Satish is pursing his Ph.D. in the Departement of Mechanical Engineering at Indian Institute of Technology Delhi. He obtained masters degree in CAD/CAM from GVPCOE Vishakapatnam, India in 2011 and bachelors of technology in mechanical engineering from Dr.S.G.I.E.T affiliated to JNTU Kakinada, India in 2007. His research interests of sheet metal operations. include material characterization of sheet metals, FEA

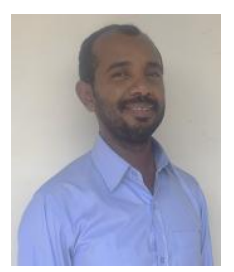

Fitsum Taye Feyissa is pursing his $\mathrm{PhD}$ in the Departement of Mechanical Engineering at Indian Institute of Technology Delhi. He obtained masters degree in Mechanical Engineering from Addis Ababa University, Ethiopia (jointly with IIT Delhi) and bachelors of science in manufacturing engineering from Adama Science and Technology University, Ethiopia. He was awarded an advanced diploma in Menschen für Menschen Germany foundation, Harar Ethiopia in 2006. His research interests include materials characterization, advanced of sheet metal forming technology, FEA of sheet metal operations and design and manufacturing of tools and dies. He is currently working in advanced sheet metal forming and characterization of cryorolled nonferrous metals. He received best BSc project award by Ethiopian Society of Mechanical Engineers in 2008 and fellowship during Ph.D. by Ethiopian government.

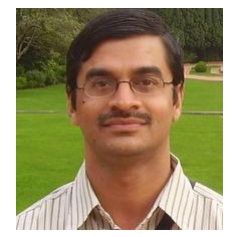

Digavalli Ravi Kumar is a professor in the Department of Mechanical Engineering, Indian Institute of Technology Delhi. His research interests include Sheet Metal Forming and FE Analysis. He published over 70 research papers in national and international journals and conferences. Dr. Ravi Kumar received the Best $R \& D$ project award in Tata Steel for the year 1997-98. He was a visiting faculty at the University of Waterloo, Canada in 2005-06. He was a Humboldt Research Fellow at the Institute for Metal Forming Technology, University of Stuttgart, Germany in 2008 and University of Erlangen-Nuremberg, Germany in 2013. He received J.M. Mahajan award for the outstanding young teacher in Mechanical Engineering in 2008 and the Teaching Excellence award in 2011 at IIT Delhi. He supervised $7 \mathrm{PhD}$ and 30 M.Tech theses. 